\title{
Geologia integrada das Folhas Jequitaí, Bocaiúva e Montes Claros (1:100.000),
}

\section{norte de Minas Gerais}

\author{
Mario Luiz de Sá Carneiro Chaves ${ }^{1}$, Kerley Wanderson Andrade², Leila Benitez ${ }^{3}$ \\ ${ }^{1}$ Centro de Pesquisa Prof. Manoel Teixeira da Costa, Instituto de Geociências da Universidade Federal de Minas Gerais, Pesquisador CNPq, \\ mchaves@ufmg.br \\ ${ }^{2}$ Mestrando em Geologia, Instituto de Geociências da Universidade Federal de Minas Gerais, GEOMIL - Serviços de Mineração Ltda, \\ kerley@geomil.com.br \\ ${ }^{3}$ Departamento de Gemologia, Universidade Federal do Espírito Santo, leilabenitez@gmail.com
}

Recebido em 17 de outubro de 2011; aceito em 20 de outubro de 2011

\begin{abstract}
RESUMO: No mapeamento geológico (1.100.000) das folhas Jequitaí, Bocaiúva e Montes Claros, executado para a CPRM - Serviço Geológico do Brasil, foram reconhecidas sequências geológicas de idades mesoproterozóica, neopreoterozóica e fanerozóica. As rochas mais antigas (Mesoproterozóico) pertencem ao Supergrupo Espinhaço (indiviso), que aflora na porção sul da região enfocada abrangendo unidades siliciclásticas estruturadas em grandes anticlinais e metamorfizadas em fácies xisto verde. O Grupo Macaúbas (Neoproterozóico) ocorre nas bordas das faixas de exposição do Supergrupo Espinhaço, constituído por quartzitos e metadiamictitos, indivisos no mapa. 0 Grupo Bambuí (Neoproterozóico tardio) representa a sequência de maior expressão superficial, de natureza pelito-carbonática, onde se reconheceram as formações Serra de Santa Helena, Lagoa do Jacaré e Serra da Saudade, da base para o topo. Na unidade intermediária foram ainda individualizados os horizontes mais potentes de rochas calcárias. Sobrepõem discordantemente a essas três sequências, depósitos cretácicos (formações Abaeté e Urucuia) e fanerozóicos (coberturas inconsolidadas). Em termos estruturais, a região constitui dois domínios: a sudeste e a leste, ocorre a margem oeste da Faixa de Dobramentos Araçuaí, em contato com o Cráton São Francisco, onde rochas do Supergrupo Espinhaço e do Grupo Macaúbas encontram-se empurradas sobre a zona cratônica. Nesse outro domínio, sinclinais e anticlinais suaves expõem principalmente rochas do Grupo Bambuí. Os principais bens minerais explorados na região constituem diamantes, calcário e quartzo.
\end{abstract}

Palavras-chave: Mapeamento Geológico, Folha Jequitaí, Folha Bocaiúva, Folha Montes Claros.

ABSTRACT: INTEGRATED GEOLOGY OF JEQUITAÍ, BOCAIÚVA AND MONTES CLAROS SHEETS (1:100.000), NORTHERN MINAS GERAIS, BRAZIL. In geological mapping $(1: 100,000)$ of the Jequitaí, Bocaiúva and Montes Claros sheets, executed to the CPRM - Geological Survey of Brazil, sequences of Mesoproterozoic, Neoproterozoic and Phanerozoic ages were recognized. The oldest rocks (Mesoproterozoic) belong to the Espinhaço Supergroup (undivided), which outcrop in the southern portion of the focused region including siliciclastic units structured in large anticlines and metamorphosed in greenschist facies. Macaúbas Group (Neoproterozoic) occurs at the edges of exposure belts of the Espinhaço Supergroup, consisting of quartzite and metadiamictite undivided on the map. The Bambuí Group (Late Neoproterozoic) represents the sequence of greater surficial expression. In this unit were recognized Serra de Santa Helena, Lagoa do Jacaré and Serra da Saudade formations, from bottom to top. In the intermediate unit were still the most powerful individual horizons of limestone. These three sequences are unconformably overlap by Cretaceous (Abaeté and Urucuia formations) and Phanerozoic (unconsolidated covers) deposits. In structural terms, the region has two different domains: in southeast and east, there is the west margin of the Araçuaí Fold Belt in contact with the São Francisco craton, where Espinhaço Supergroup and Macaúbas Group rocks are overlapped on the cratonic zone. In this other domain large and low grade synclines and anticlines expose mainly Bambuí Group rocks. The most important mineral resources of the region are diamonds, limestone and quartz.

Keywords: Geological mapping, Jequitaí sheet, Bocaiúva sheet, Montes Claros sheet.

\section{INTRODUÇÃO}

A região norte de Minas Gerais tem se constituído nas últimas décadas como uma das últimas fronteiras exploratórias desse estado, principalmente envolvendo o setor agropecuário, mas também no setor minerário através de campanhas exploratórias de várias commodities, a exemplo de minério de ferro, ouro, calcário, quartzo e diamantes. Integrando partes do "Programa Geologia do Brasil" da CPRM - Serviço Geológico do Brasil, diversas folhas geológicas foram cartografadas nessa região a partir de 2004, na escala 1:100.000, possuindo entre seus propósitos justamente a melhoria do conhecimento da geologia básica, para que esta sirva de instrumento de incentivo e fomento a novas campanhas de prospecção (Chaves \& Benitez, 2006; Chaves \& Andrade, 2009, 2011).
Nesse contexto, foram levantadas as folhas adjacentes Jequitaí, Bocaiúva e Montes Claros, tendo como objetivos principais a estratigrafia, geologia estrutural e recursos minerais das mesmas. Os presentes autores, tendo o primeiro como coordenador, integram um extenso grupo que participou das diversas etapas de mapeamento dessas folhas (relacionado nos agradecimentos), contando como coordenador geral do projeto o Prof. Dr. Antônio Carlos Pedrosa Soares (CPMTCIGC/UFMG).

\section{CONTEXTO GEOLÓGICO REGIONAL}

$O$ conjunto de folhas estudado localiza-se na porção centro-norte Minas Gerais, entre a Serra do Espinhaço (a leste) e o Rio São Francisco (a oeste) (Figura 1). Em termos geotectônicos, a região está inserida na zona de transição entre o Cráton São Francisco e a Faixa de Dobramentos Araçuaí. A zona cratônica, na definição original de Almeida (1977) 
constitui uma área plataformal cujo embasamento se consolidou em tempos pré-brasilianos, servindo assim de antepaís para as faixas de dobramentos estabelecidas no Brasiliano. Alkmim et al. (1993) aperfeiçoaram esse conceito, sendo então o cráton "entendido como uma feição do Proterozóico Superior, ou seja, moldada pelo Evento Brasiliano, embora tenha se consolidado como segmento da litosfera continental no Arqueano".

A Faixa Araçuaí corresponde ao lado brasileiro do Orógeno Araçuaí-Congo Ocidental, parte do sistema orogenético Brasiliano-Pan Africano. Segundo Pedrosa-Soares et al. (2001), em sua evolução podem ser reconhecidos: (1) um estágio de rifteamento continental com importante contribuição de sedimentação glaciogênica (1,0-0,9 Ga), (2) o desenvolvimento de uma margem passiva (800 Ma) e, (3) com o fechamento dessa bacia oceânica, a geração de um arco magmático (625-570 Ma). Nessa conceituação, exclui-se de tal domínio a Faixa Espinhaço, a qual, no entanto, é incluída no mesmo contexto por outros autores (e.g., Almeida, 1977; Uhlein et al., 1986, 1998).

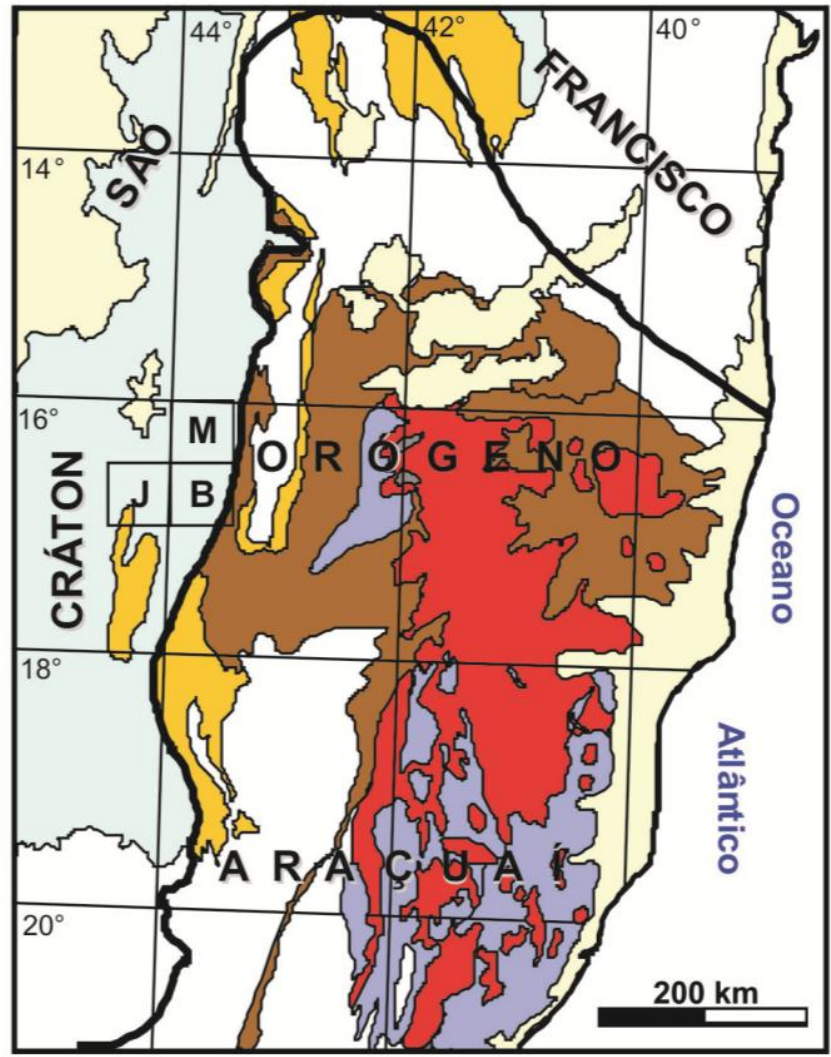

Coberturas mesozóicas e cenozóicas

\section{CAMBRIANO E NEOPROTEROZÓICO}

$\square$ Coberturas cratônicas

Magmatismo pré- a pós-colisional

Bacias orogênicas

Rifte, margem passiva e ofiolitos

\section{ESTATERIANO E MESOPROTEROZÓICO}

Supergrupo Espinhaç o e correlatos

\section{ARQUEANO E PALEOPROTEROZÓICO}

$\square$ Embasamento indiviso

Limite entre Cráton do São Francisco

e Orógeno Araçuaí

Figura 1: Situação das folhas geológicas Jequitaí (J), Bocaiúva (B) e Montes Claros (M), em relação ao contexto geotectônico envolvendo o Cráton São Francisco e o Orógeno Araçuaí.

O grau metamórfico predominante é o da fácies xisto verde baixo (Uhlein et al., 1986, 1998, PedrosaSoares et al., 2001). Em termos litoestratigráficos, afloram rochas paleoproterozóicas tardias e mesoproterozóicas do Supergrupo Espinhaço, bem como rochas neoproterozóicas do Supergrupo São Francisco, representadas pelos grupos Macaúbas e Bambuí. A oeste da Serra do Espinhaço, litotipos do Grupo Bambuí predominam largamente, e sua sedimentação provavelmente está associada a uma bacia do tipo foreland, alimentada na maior parte por fontes a oeste, nos domínios da Faixa de Dobramentos Brasília (Pimentel et al., 2011).

Souza (1985), reconheceu quatro grandes unidades tectonogeológicas na região da Folha
Pirapora (1:250.000), a qual abrange as duas folhas ao sul da área enfocada: (1) Rifte intracratônico (Mesoproterozóico); (2) Bacia epicontinental marinha (Neoproterozóico); (3) Bacia tipo sinéclise (Mesozóico); (4) Cobertura superimposta final (Cenozóico). Tais domínios de natureza geotectônica correspondem, respectivamente, às seguintes unidades litoestratigráficas: (1) Supergrupo Espinhaço, (2) Supergrupo São Francisco, (3) Grupo Areado, e (4) Depósitos Detrítico-Lateríticos, Colúvio-Eluviais e Aluvionares. As duas principais sequências em termos geológicos, metalogenéticos e de representatividade regional constituem os supergrupos Espinhaço e São Francisco. 


\section{3.- GEOLOGIA DA ÁREA}

Ao longo do período de mapeamento das três folhas foram levantadas 1.739 estações de campo, assim distribuídas: Folha Jequitaí, 535 pontos; Folha Bocaiúva, 590 pontos; e Folha Montes Claros, 614 pontos. Nesse trabalho, foram coletadas 306 amostras de rochas, das quais se confeccionaram 72 lâminas delgadas. Para a caracterização estrutural, utilizaram-se dados de 915 medidas de acamadamento, 717 medidas de foliação e 442 medidas de fraturas e/ou veios de quartzo. Cerca de 100 depósitos minerais foram cadastrados nessas folhas.

\section{1 - Estratigrafia}

Na região, afloram unidade neoproterozóicas dos supergrupos Espinhaço e São Francisco, além de coberturas fanerozóicas pertencentes ao Grupo Areado e à Formação Urucuia. Os depósitos superficiais, na maior parte inconsolidados, constituem três tipos: detrítico-lateríticos, colúvioeluviais e aluvionares, todos cenozóicos (Figura 2).

\subsection{1 - Supergrupo Espinhaço}

Litotipos do Supergrupo Espinhaço estão presentes no extremo norte da Serra do Cabral e no núcleo da Serra da Água Fria, respectivamente ao sul e centro-norte da Folha Jequitaí. Na Folha Bocaiúva, ocorre no fechamento norte da Serra do Espinhaço Meridional, ao sul desta folha.

Embora representado indivisamente no mapa geológico (Figura 2), tal sequência é composta na região por três formações: Galho do Miguel, Santa Rita e Córrego dos Borges; as duas últimas afloram exclusivamente na Serra do Cabral (Folha Jequitaí). Essas formações, descritas originalmente por Pflug (1968) e Schöll \& Fogaça (1979), incluem sucessivamente, da base para o topo, quartzitos finos com alto grau de pureza e estratificações cruzadas de grande porte; metassiltitos e metargilitos; e quartzitos finos a médios com estratificações plano-paralelas.

Esta porção do Supergrupo Espinhaço foi depositada no Mesoproterozóico (Dossin et al., 1990; Chemale Jr. et al., 2010), em período ainda alvo de discussões. Para a sequência como um todo, prevalece a hipótese de uma sedimentação em ambiente de rifte continental que evoluiu para uma bacia intracratônica ensiálica, com registro das fases pré-rifte, rifle, transicional e flexural (Dussin \& Dussin, 1995; Martins-Neto, 2000). Sua porção basal (Grupo Diamantina), que inclui a Formação Galho do Miguel, é representada por sedimentos eólicos e marinho rasos. As duas formações superiores fazem parte do Grupo Conselheiro Mata, e denotam condições de sedimentação francamente marinhas.

\subsection{2 - Supergrupo São Francisco}

Essa sequência predomina sobre a maior parte da região enfocada, sendo constituída pelos grupos Macaúbas e Bambuí. O Grupo Macaúbas, basal, está representado indivisamente no mapa geológico, e inclui as formações Duas Barras (quartzitos impuros), Jequitaí e Serra do Catuni (metadiamictitos). As duas últimas são cronocorrelatas e significam uma sedimentação predominantemente glaciomarinha intracratônica (Jequitaí) e a outra, mais distal, nos domínios da Faixa Araçuaí.

O Grupo Bambuí, de cobertura cratônica, é representado por suas formações Serra de Santa Helena, Lagoa do Jacaré e Serra da Saudade, individualizadas no mapa geológico. Elas compõem respectivamente uma sucessão de siltitos na base, siltitos, folhelhos rítmicos e calcários na porção intermediária, e argilitos e diamictitos no topo (Figura 2).

\subsection{3 - Coberturas fanerozóicas}

Incluem-se aqui os depósitos continentais do Grupo Areado (Formação Abaeté) e da Formação Urucuia, do Cretáceo Inferior e Superior, respectivamente. Tais depósitos ocorrem como manchas reliquiares do topo da paisagem, a primeira principalmente no âmbito da Folha Jequitaí, e a outra exclusivamente na Folha Montes Claros. A Formação Abaeté é composta por conglomerados polimíticos, clasto-sustentados, depositados em sistemas fluviais e de leques aluviais, enquanto a Formação Urucuia é constituída por arenitos finos, vermelhos, de sedimentação eólica.

Complementam a sequência, depósitos principalmente inconsolidados, cenozóicos, que formam coberturas detrítico-lateríticas, colúvioeluviais e aluvionares (Figura 2).

\section{2 - Síntese dos dados geocronológicos} disponíveis

No preenchimento da bacia Espinhaço, a deposição sedimentar iniciou-se por volta de 1,71 $\mathrm{Ga}$, idade fornecida por $\mathrm{U}-\mathrm{Pb}$ em zircões de metavulcânicas associadas à porção basal do Supergrupo Espinhaço (Machado et al., 1989; Dussin \& Dussin, 1995). Sua idade limite inferior é ainda alvo de discussões; Uhlein (1991) e Uhlein et al. (1998) estimaram o período total de sedimentação em cerca de 300 Ma. Martins (2006) efetuou datações U-Pb em zircões detríticos da Formação Resplandecente, aflorante a leste da Folha Bocaiúva. Essa unidade, por suas características físicas e tectono-estratigráficas tem sido por diversas vezes considerada uma equivalente da Formação Galho do Miguel em estudos do primeiro autor (e.g., Chaves, 1997; Chaves et al., 1999). As idades inferiores 
obtidas para tais zircões variaram em torno de 1.200 Ma, a qual representa a melhor estimativa até o momento da idade máxima de deposição do Supergrupo Espinhaço.

No Grupo Macaúbas, análises U-Pb dos zircões detríticos mais jovens da Formação Duas Barras situaram-se ao redor de $900 \mathrm{Ma}$, considerada a idade máxima de deposição da base desse grupo (Martins, 2006; Babinski et al., 2011). Estudos radiométricos sobre as idades de deposição da Formação Serra do Catuni, bem como de sua congênere cratônica, a Formação Jequitaí (Babinski et al., 2007, 2011), encontraram zircões detríticos mais jovens em ca. 933 Ma. Assim, os eventos que marcaram a deposição do Grupo Macaúbas são balizados entre $900 \mathrm{Ma}$ e possivelmente $750 \mathrm{Ma}$, idade do cap carbonate da Formação Sete Lagoas, do Grupo Bambuí (Santos et al., 2000; Babinski \& Kaufman, 2003). Pimentel et al. (2011), por sua vez, efetuaram datações nas principais sequências da Faixa Brasília, a oeste do Cráton São Francisco, incluindo os metadiamictitos da Formação Jequitaí. Embora nessa formação predominem grãos paleo e mesoproterozóicos, foram encontrados alguns mais novos, por volta de $850 \mathrm{Ma}$, os quais serviram para "abaixar" ainda mais a idade de sedimentação do Grupo Macaúbas.
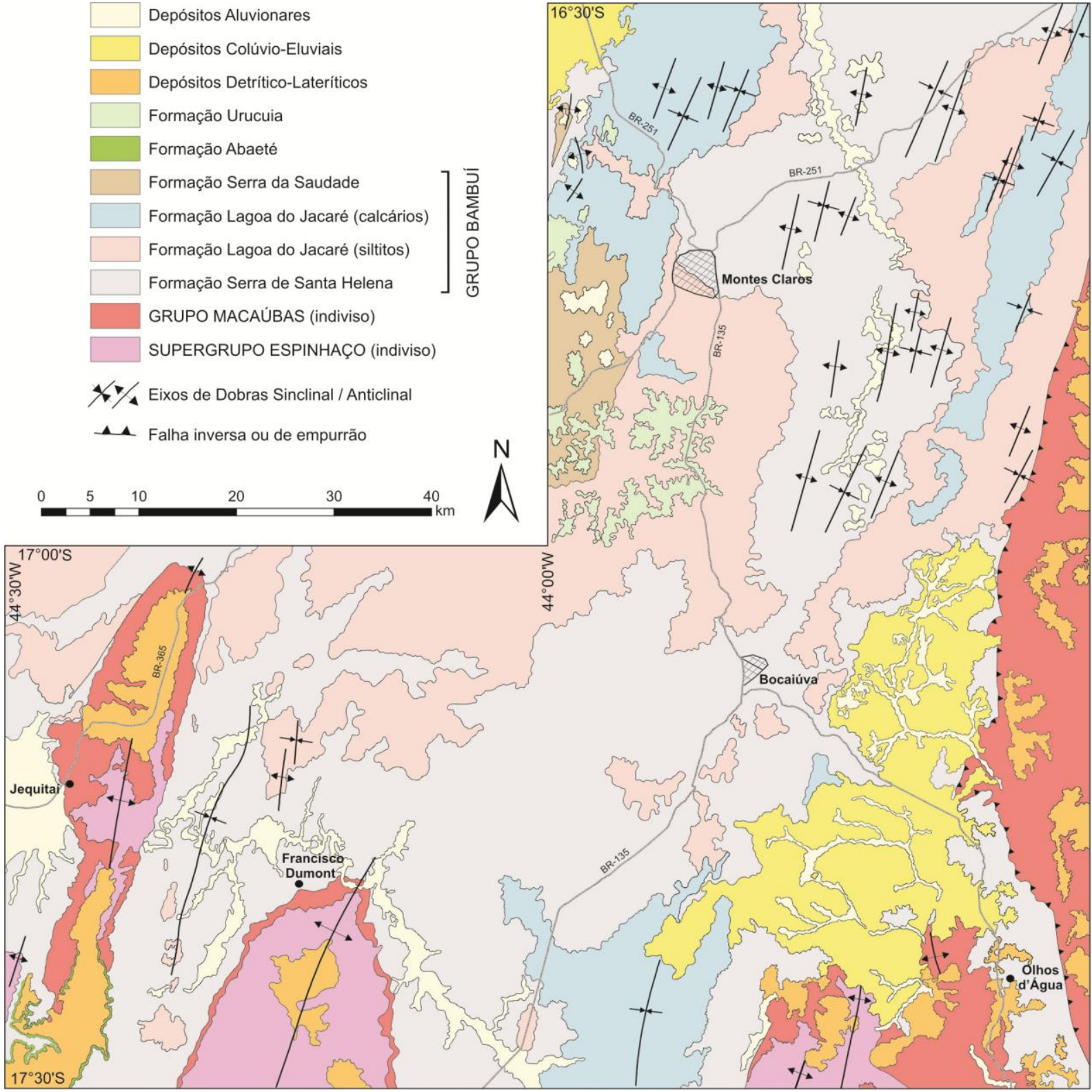

Figura 2: Mapa geológico integrado das folhas Jequitaí, Bocaiúva e Montes Claros (parcial e modificado de Chaves \& Benitez, 2006; e Chaves \& Andrade, 2009, 2011) 
A respeito do Grupo Bambuí, idades radiométricas recentemente obtidas por Babinski \& Kaufman (2003) e Babinski (2005), dataram o cap carbonate basal da Formação Sete Lagoas em $740 \pm 22 \mathrm{Ma}$, pelo método $\mathrm{Pb} / \mathrm{Pb}$. Um número expressivo de análises $\mathrm{U}-\mathrm{Pb}$ em zircão detrítico foi efetuado por Rodrigues (2008) para todas as formações desse grupo, as quais evidenciaram forte proporção de material datado no final do Neoproterozóico. No trabalho de Pimentel et al. (2011), em relação à mesma sequência, apresentase o padrão da parte superior da Formação Sete Lagoas, também com predominância de zircões neoproterozóicos, os mais novos com idades por volta de $620 \mathrm{Ma}$. Esses dados demonstram que a deposição do Grupo Bambuí ocorreu perto do final do Neoproterozóico e aproximadamente posterior ao pico do metamorfismo registrado na Faixa Brasília, reforçando a idéia de que tais depósitos representem uma bacia foreland em relação à evolução final do orógeno, como previamente sugerido por Chang et al. (1988).

\section{GEOLOGIA ESTRUTURAL}

A principal feição estrutural presente nas folhas enfocadas é o limite da Faixa de Dobramentos Araçuaí com o Cráton São Francisco, dado a leste das folhas Bocaiúva e Montes Claros. Nesta região, as rochas do Grupo Macaúbas encontram-se cavalgando as unidades do Grupo Bambuí. A Faixa Araçuaí se desenvolveu durante o Ciclo Brasiliano, entre $680 \mathrm{Ma}$ e $490 \mathrm{Ma}$, e foi responsável pela deformação e metamorfismo de fácies xisto verde, na própria faixa (Supergrupo Espinhaço e Grupo Macaúbas), bem como por anquimetamorfismo no domínio cratônico adjacente (Grupo Bambuí).

O limite do cráton é dado por falhas desde alto até baixo ângulo com desenvolvimento de uma foliação plano-axial de alto ângulo, mergulhando forte para leste. $O$ padrão de dobramentos inclui amplos sinclinais e anticlinais de eixos NNE-SSW, localmente falhados (Figura 3A), e os mergulhos para leste em geral são mais suaves que os opostos. As foliações são plano-axiais a tais dobras, e mergulham mais fortemente para NE (Figura 3B). No domínio da faixa de dobramentos, tais foliações são um pouco mais suaves, e tem a mesma direção da master fault limita o cráton (Figuras 2 e 3B). Principalmente ao sul da região, ocorre uma outra fase, tardia, responsável por duplos caimentos dessas dobras regionais de eixos em torno de nortesul, que mergulhar por baixo da cobertura cratônica as rochas mais antigas, do Supergrupo Espinhaço e do Grupo Macaúbas.

\section{DEPÓSITOS MINERAIS}

Os bens minerais mais importantes explorados e de grande potencial na região incluem quartzo, calcário e diamantes. O primeiro é lavrado em uma grande mina (Mina do Moinho, em Olhos d’Água), Folha Bocaiúva, e em dezenas de pequenos garimpos nesta e nas outras folhas. Sua gênese está ligada a veios hidrotermais originados de fluidos tardios, por remobilização de sílica das encaixantes durante os estágios finais da deformação brasiliana, por volta de $490 \mathrm{Ma}$ (Chaves et al., 2010a).

O calcário, embora lavrado exclusivamente em algumas minas de pequeno a médio porte nos arredores de Montes Claros, na folha homônima, possui um grande potencial dado pela existência de pequenas serras inteiras deste material, no âmbito da Formação Lagoa do Jacaré, principalmente nas folhas Bocaiúva e Montes Claros. Análises químicas efetuadas demonstram a excelente qualidade deste material para a indústria cimenteira (Chaves \& Andrade, 2009).

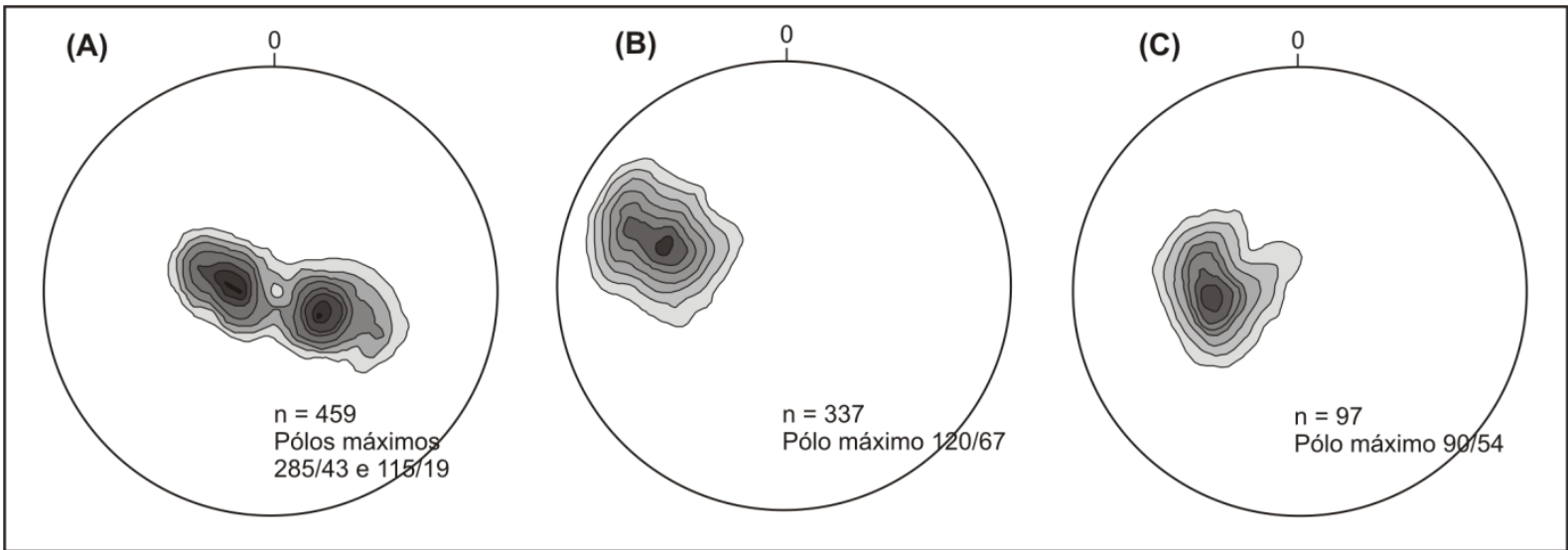

Figura 3: Diagramas de pólos equiareais para medidas de acamadamento (A) e de foliação (B) de litotipos pelíticos do Grupo Bambuí, e de foliação dos metadiamictitos e quartzitos do Grupo Macaúbas (C) a leste da falha de empurrão que limita o Cráton São Francisco com a Faixa Araçuaí, na Folha Bocaiúva. 
O diamante está presente em sua maior parte nos arredores de Jequitaí e Francisco Dumont (Folha Jequitaí), e com menor expressão nos arredores de Olhos d'Água (Folha Bocaiúva). Sua origem se relaciona aos metadiamictitos neoproterozóicos da Formação Jequitaí, e possivelmente ainda aos conglomerados cretácicos da Formação Abaeté (Karfunkel \& Chaves, 1995; Chaves et al., 2010b). A fonte primária de tais depósitos, desconhecida, encontra-se provavelmente soterrada sob os depósitos do Grupo Bambuí, na zona cratônica (Chaves, 1997).

\section{CONSIDERAÇÕES FINAIS}

No presente trabalho foram apresentados dados integrativos entre estratigrafia, geologia estrutural e recursos minerais das folhas Jequitaí, Bocaiúva e Montes Claros (1:100.000). A evolução geológica regional pode ser sumarizada em seis etapas principais, assim caracterizadas em função dos dados geocronológicos disponíveis: (1) Deposição dos sedimentos siliciclásticos do Supergrupo Espinhaço, no Mesoproterozóico, com início em $\sim 1,71 \mathrm{Ga}$ e final ainda alvo de discussões, em contexto geral de uma bacia do tipo rifte intracratônico (Dussin \& Dussin, 1995; Martins-Neto, 2000); (2) Sedimentação clástica marinha e glaciomarinha do Grupo Macaúbas, intra a pericratônica, no Neoproterozóico entre 850 Ma e 750(?) Ma (Martins, 2006; Babinski et al., 2007, 2011); (3) Sedimentação pelito-carbonática do Grupo Bambuí, no Neoproterozóico entre 720 Ma e 620(?) Ma, em mar epicontinental no contexto de uma bacia de antepaís (foreland) em relação a Faixa Brasília, a oeste do cráton (Babinski, 2005; Babinski \& Kaufman, 2003; Pimentel et al., 2011); (4) Orogênese brasiliana na Faixa Araçuaí, responsável por deformação, dobramentos e metamorfismo no Neoproterozóico entre 620 Ma e $490 \mathrm{Ma}$; (5) Sedimentação continental sobre o cráton, representada pelas formações Abaeté e Urucuia, no período entre 130 Ma e 65 Ma (Grossi-Sad et al., 1971; Ladeira et al., 1971; Sgarbi, 2000; Sgarbi et al., 2001); (6) Desenvolvimento generalizado de coberturas superficiais, desde o Paleógeno até os dias atuais (King, 1956)

\section{7 - AGRADECIMENTOS}

Os autores expressam seus agradecimentos à CPRM - Serviço Geológico do Brasil, pela incentiva e apoio financeiro tendo em vista o mapeamento geológico das respectivas folhas, como parte de seu "Programa Geologia do Brasil". Na execução dos trabalhos de mapeamento e escritório, contou-se com a importante participação dos discentes: Carlos J. E. Silva, Christianne R. O. Mariz, Coralie H. Dias Felipe C. Barbosa, Josué M. Souza Júnior, Leandro S.
Bicalho, Luciano H. G. Magalhães e Moisés S. Oliveira. $O$ primeiro autor é bolsista de produtividade em pesquisa do $\mathrm{CNPq}$, ao qual também agradece.

\section{REFERÊNCIAS BIBLIOGRÁFICAS}

Alkmim F.F., Brito-Neves B.B., Alves J.A.C. 1993. Arcabouço tectônico do Cráton do São Francisco - uma revisão. In: Dominguez, J.M.L. \& Misi, A. (eds.), O Cráton do São Francisco. Reunião preparatória do II Simpósio sobre o Cráton do São Francisco. Salvador, SBG/Núcleo BA-SE/SGM/CNPq, p.45-62.

Almeida, F.F.M. 1977. O Cráton do São Francisco. Revista Brasileira de Geociências, 7: 349-364.

Babinski M. 2005. A idade do Supergrupo São Francisco: revisão e implicações nas glaciações neoproterozóicas. In: SIMPÓSIO SOBRE O CRÁTON DO SÃO FRANCISCO, Salvador, Short Papers..., 3: 135-138.

Babinski M. \& Kaufman A.J. 2003. First direct dating of a Neoproterozoic post-glacial cap carbonate. In: SOUTH AMERICAN SYMPOSIUM ON ISOTOPE GEOLOGY, 4, Salvador, Short Papers..., 1: 321-323.

Babinski M., Pedrosa-Soares A.C., Martins M., Liu D., Noce C.M., Karfunkel J. 2007. Geocronologia U-Pb SHRIMP em zircões detríticos do Grupo Macaúbas: implicações na idade de deposição e proveniência dos sedimentos. In: SIMPÓSIO DE GEOLOGIA DE MINAS GERAIS, 14, Diamantina, Resumos..., p.33.

Babinski M., Pedrosa-Soares A.C., Trindade R.I.F., Martins M., Noce C.M., Liu D. 2011. Neoproterozoic glacial deposits from the Araçuaí orogen, Brazil: age, provenance and correlations with the São Francisco craton and West Congo belt. Gondwana Research, 20 (in press).

Chang H.K., Miranda F.P., Magalhães L., Alkmim F.F. 1988. Considerações sobre a evolução tectônica da Bacia do São Francisco. In: CONGRESSO BRASILEIRO DE GEOLOGIA, 35, Belém, Anais..., 5: 2076-2090.

Chaves M.L.S.C. 1997. Geologia e mineralogia do diamante da Serra do Espinhaço em Minas Gerais. São Paulo, Tese de Doutoramento, IG/USP, 289p.

Chaves M.L.S.C. \& Benitez L. 2006. Folha Jequitaí 1:100.000. Brasília, Programa Geologia do Brasil, Convênio CPRMIGC/UFMG, Relatório Final, 45p.

Chaves M.L.S.C. \& Andrade K.W. 2009. Folha Bocaiúva 1:100.000. Brasília, Programa Geologia do Brasil, Convênio CPRMIGC/UFMG, Relatório Final, 73p.

Chaves M.L.S.C. \& Andrade K.W. 2011. Folha Montes Claros 1:100.000. Brasília, Programa Geologia do Brasil, Convênio CPRM-IGC/UFMG, Relatório Final, 91p.

Chaves M.L.S.C., Karfunkel J., Addad J. 1999. Geologia da região diamantífera de Grão Mogol, Minas Gerais. Geociências, 18: 129-155.

Chaves M.L.S.C., Brandão P.R.G., Buhn,B. 2010a. Monazita em veios de quartzo da Serra do Espinhaço Meridional (MG): mineralogia, idades LA-ICP-MS e implicações geológicas. Revista Brasileira de Geociências, 40: 506-515

Chaves M.L.S.C., Guimarães J.T., Andrade K.W. 2010b. Litofácies glaciomarinhas na Formação Jequitaí (MG) e suas implicações na distribuição regional de diamantes. Revista Brasileira de Geociências, 40: 516-526.

Chemale Jr. F., Dussin I.A., Martins M.S., Alkmim F.F., Queiroga G. 2010. The Espinhaço Supergroup in Minas Gerais: a Stenian 
basin? In: SOUTH AMERICAN SYMPOSIUM ON ISOTOPE GEOLOGY, 7, Brasília, Proceedings..., p.552-555.

Dossin I.A., Dossin T.M., Chaves M.L.S.C. 1990. Compartimentação estratigráfica do Supergrupo Espinhaço em Minas Gerais: os grupos Diamantina e Conselheiro Mata. Revista Brasileira de Geociências, 20: 178-186.

Dussin I.A. \& Dussin T.M. 1995. Supergrupo Espinhaço: modelo de evolução geodinâmica. Geonomos, 3: 19-26.

Grossi-Sad J.H., Cardoso R.N., Costa M.T. 1971. Formações cretácicas em Minas Gerais: uma revisão. Revista Brasileira de Geociências, 1: 2-13.

Karfunkel J. \& Chaves M.L.S.C. 1995. Conglomerados cretácicos da Serra do Cabral, Minas Gerais: um modelo para a redistribuição colúvio-aluvionar dos diamantes do Médio São Francisco. Geocências, 14: 59-72.

King L. 1956. A geomorfologia do Brasil Oriental. Revista Brasileira de Geografia, 18: 147-266.

Ladeira E., Braun O.P.G., Cardoso R.N., Hasui Y. 1971. O Cretáceo em Minas Gerais. In: Congresso Brasileiro de Geologia, Anais do..., São Paulo, 25: 15-31.

Machado N., Schrank, A., Abreu F.R., Knauer L.G., Almeida-Abreu P.A. 1989. Resultados preliminares da geocronologia U-Pb na Serra do Espinhaço Meridional. In: SIMPÓSIO DE GEOLOGIA DE MINAS GERAIS, 5, Belo Horizonte, Anais..., p.171-174.

Martins M.S. 2006. Geologia dos diamantes e carbonados da bacia do Rio Macaúbas (MG). Belo Horizonte, Tese de Doutoramento, IGC/UFMG, 231p.

Martins-Neto M.A. 2000. Tectonic and sedimentation in a Paleo/Mesoproterozoic rift-sag basin (Espinhaço basin, southeastern Brazil). Precambrian Research, 103: 147-173.

Martins-Neto M.A. \& Alkmim F.F. 2001. Estratigrafia e evolução tectônica das bacias proterozóicas do Paleocontinente São Francisco e suas margens: registro da quebra de Rodínia e colagem de Gondwana. In: Pinto C.P. \& Martins-Neto M.A. (eds.), Bacia do São Francisco: Geologia e Recursos Naturais. Belo Horizonte, SBG-MG, p.31-54.

Pedrosa-Soares A.C., Noce, C.M., Wiedmann C.M., Pinto C.P. 2001. The Araçuaí-West Congo Orogen in Brazil: an overview of a confined orogen formed during Gondwanaland assembly. Precambrian Research, 110: 307-323.
Pflug R. 1968. Observações sobre a estratigrafia da região de Diamantina, Minas Gerais. Notas Preliminares e Estudos DGM/DNPM, 14: 1-20.

Pflug R. \& Renger F.E. 1973. Estratigrafia e evolução geológica da margem sudeste do cráton Sanfranciscano. In: CONGRESSO BRASILEIRO DE GEOLOGIA, 27, Aracaju, Anais..., 2: 5-19.

Pimentel M.M., Rodrigues J., DellaGiustina, M.E., Junges, S., Matteini, M., Armstrong, R. 2011. The tectonic evolution of the Neoproterozoic Brasilia Belt, central Brazil, based on SHRIMP and LA-ICPMS U-Pb sedimentary provenance data: a review. Journal of South American Earth Sciences, 31: 345357.

Santos R.V., Alvarenga C.J.S., Dardenne M.A., Sial A.N., Ferreira V.P. 2000. Carbon and oxygen isotope profiles across MesoNeoproterozoic limestones from Central Brazil: Bambuí and Paranoá groups. Precambrian Research, 104: 107-122.

Schöll W.U. \& Fogaça A.C.C. 1979. Estratigrafia da Serra do Espinhaço na região de Diamantina (MG). In: SIMPÓSIO DE GEOLOGIA DE MINAS GERAIS, 1, Diamantina, Atas..., p.55-73.

Sgarbi G.N. 2000. The Cretaceous Sanfranciscan Basin, eastern plateau of Brazil. Revista Brasileira de Geociências, 30: 450452.

Sgarbi G.N.C., Sgarbi P.B.A., Campos J.E.G., Dardenne M.A., Penha U.C. 2001. Bacia Sanfranciscana: o registro fanerozóico da Bacia do São Francisco. In: Pinto C.P. \& Martins-Neto M.A. (eds.): Bacia do São Francisco: Geologia e Recursos Naturais. Belo Horizonte, SBG/MG, p.93-138.

Souza A.A. 1985. Projeto Mapas Metalogenéticos e de Previsão de Recursos Minerais, Folha SE.23-X-C Pirapora. Belo Horizonte, Convênio DNPM/CPRM, 50p.

Uhlein A. 1991. Transição cráton-faixa dobrada: um exemplo do Cráton do São Francisco e da Faixa Araçuaí (Ciclo Brasiliano) no Estado de Minas Gerais. Aspectos estratigráficos e estruturais. São Paulo, Tese de Doutoramento, IG/USP, 295p.

Uhlein A., Dossin I.A., Chaves M.L.S.C. 1986. Contribuição à geologia estrutural e tectônica das rochas arqueanas e proterozóicas da Serra do Espinhaço Meridional - MG. In CONGRESSO BRASILEIRO DE GEOLOGIA, 32, Anais..., Goiânia, 3: $1191-1201$

Uhlein A., Trompette R.R., Egydio-Silva M. 1998. Proterozoic rifting and closure, SE border of the São Francisco Craton, Brazil. Journal of South American Earth Sciences, 11: 191-203. 